\title{
Exploration of a Panel of Urine Biomarkers of Kidney Disease in Two Paediatric Cohorts With Type 1 Diabetes Mellitus of Differing Duration
}

Letizia Zeni ( $\sim$ letizia.zeni@gmail.com )

ASST Spedali Civili di Brescia: Azienda Socio Sanitaria Territoriale degli Spedali Civili di Brescia https://orcid.org/0000-0001-9221-5698

Anthony G.W. Norden

University College London

\section{Elena Prandi}

ASST Spedali Civili di Brescia: Azienda Socio Sanitaria Territoriale degli Spedali Civili di Brescia

\section{Carolina Canepa}

Royal Berkshire Hospital

\section{Keith Burling}

Cambridge University Hospitals NHS Foundation Trust

Katherine Simpson

Cardiff University College of Biomedical and Life Sciences

\section{Barbara Felappi}

ASST Spedali Civili di Brescia: Azienda Socio Sanitaria Territoriale degli Spedali Civili di Brescia

Alessandro Plebani

University of Brescia: Universita degli Studi di Brescia

\section{Giovanni Cancarini}

University of Brescia Department of Medical and Surgical Sciences: Universita degli Studi di Brescia

Dipartimento Specialita Medico-Chirurgiche Scienze Radiologiche e Sanita Pubblica

\section{Pietro Manuel Ferraro}

Fondazione Policlinico Universitario Agostino Gemelli IRCCS

\section{Donald Fraser}

Cardiff University College of Biomedical and Life Sciences

\section{Robert J. Unwin}

University College London

\section{Research Article}

Keywords: Diabetic Kidney Disease, Urinary Biomarkers, Type 1 Diabetes Mellitus, Retinol-Binding Protein 4, Kidney Injury Molecule-1, MicroRNA, Albuminuria 
Posted Date: January 25th, 2022

DOI: https://doi.org/10.21203/rs.3.rs-1260843/v1

License: (c) (i) This work is licensed under a Creative Commons Attribution 4.0 International License. Read Full License 


\section{Exploration of a panel of urine biomarkers of kidney disease in two paediatric cohorts with Type 1}

\section{diabetes mellitus of differing duration}

Letizia Zeni, MD, ${ }^{1,2, *}$

Anthony G.W. Norden, MBBS, PhD, ${ }^{3}$

Elena Prandi, MD, ${ }^{4}$

Carolina Canepa, MD, ${ }^{5}$

Keith Burling, ${ }^{6}$

Katherine Simpson, ${ }^{7}$

Barbara Felappi ${ }^{4}$

Alessandro Plebani, MD, $\mathrm{PhD}^{4}$

Giovanni Cancarini, MD, ${ }^{8}$

Pietro Manuel Ferraro, MD, PhD, ${ }^{9,10}$

Donald Fraser, MBChB PhD, ${ }^{7}$

Robert J. Unwin BM, PhD, FRCP ${ }^{3}$

1 Nephrology Unit, Azienda Socio-Sanitaria Territoriale degli Spedali Civili di Brescia, Piazzale Spedali Civili, 1 - 25123, Brescia, Italy

2 Università degli Studi della Campania "Luigi Vanvitelli", Viale Abramo Lincoln n. 5 - 81100 Caserta, Italy.

3 Department of Renal Medicine, Royal Free Hospital Trust, University College London, Rowland Hill Street London NW3 2PF England

4 Pediatrics Clinic, Department of Clinical and Experimental Sciences, University of Brescia and ASST Spedali Civili of Brescia, Piazzale Spedali Civili, 1 - 25123, Brescia, Italy

5 Department of Nephrology, Royal Berkshire Hospital, Reading United Kingdom

6 Core Biochemical Assay Laboratory Cambridge University Hospitals NHS Foundation Trust Hills Road Cambridge CB2 0QQ England

7 Wales Kidney Research Unit, Division of Infection and Immunity, School of Medicine, College of Biomedical and Life Sciences, Cardiff University, Cardiff, United Kingdom; Cardiff University, Cardiff, United Kingdom.

8 Nephrology, Department of Medical and Surgical Specialties, Radiological Science and Public Health, University of Brescia, Brescia, Italy.

9 U.O.S. Terapia Conservativa della Malattia Renale Cronica, U.O.C. Nefrologia, Fondazione Policlinico Universitario A. Gemelli IRCCS, Largo Agostino Gemelli 8, 00168, Roma, Italia

10 Università Cattolica del Sacro Cuore, Roma, Italia

*Corresponding Author: letizia.zeni@gmail.com, +39030.3995626 


\begin{abstract}
Background The pathogenesis of diabetic kidney disease (DKD) is complex and involves both glomerular and tubular dysfunction. A global assessment of kidney function is necessary to stage DKD, a progressive kidney disease that is likely to begin in childhood. The present study evaluated whether kidney injury biomarkers identified as early DKD biomarkers in adults have any predictive value in the very early stages of childhood diabetes.
\end{abstract}

Methods We measured urine free RBP4 (UfRBP4), albumin (UAlb), kidney injury molecule-1 (KIM-1) and the microRNAs miR-155, miR-126 and miR-29b in two cohorts of paediatric T1DM patients without evidence of $\mathrm{DKD}$, but with diabetes of short-duration, $\leq 2.5$ years $(\mathrm{SD}, \mathrm{n}=25$ ) or of long-duration, $\geq 10$ years (LD, $n=29)$; non-diabetic siblings $(H, n=26)$ were recruited as controls. A p value $<0.05$ was considered significant for all results.

Results UfRBP4 and UAlb were not significantly different across the three groups. No differences were found in KIM-1 excretion between any of the three groups. UfRBP4 was correlated with UAlb in all three groups ( $\mathrm{r}$ 0.49; $\mathrm{p}<0.001$ ), whereas KIM-1 showed no correlation with albumin excretion. Among microRNAs, miR-29b was higher in all diabetic children compared with the $\mathrm{H}$ control group ( $\mathrm{p}=0.03$ ), whereas miR-155 and miR-126 were not significantly different. No differences were found between the SD and LD groups for all three microRNAs. No associations were identified between these biomarkers with sex, age, BMI, eGFR, T1DM duration or glycaemic control.

\title{
Conclusions
}

UfRBP4, KIM-1, miR-155, and miR-126 were unaffected by the presence and duration of diabetes, whereas miR-29b showed a modest elevation in diabetics, regardless of duration. These data support the specificity of a panel of urine biomarkers as later DKD biomarkers, rather than any relationship to diabetes per se or its duration, and not as early DKD biomarkers in a paediatric setting. 
Keywords:

- Diabetic Kidney Disease

- Urinary Biomarkers

- Type 1 Diabetes Mellitus

- Retinol-Binding Protein 4

- Kidney Injury Molecule-1

- MicroRNA

- Albuminuria 


\section{List of Abbreviations}

DKD: diabetic kidney disease

TQDM: Type1 Diabetes Mellitus

UfRBP4: urine free Retinol-binding protein 4

UAlb: albumin

KIM-1 Kidney injury molecule-1

SD: diabetes of short-duration

LD: diabetes of long-duration

H: non-diabetic siblings

LMWP: low molecular weight protein

CAKUT: congenital anomalies of the kidney and urinary tract eGFR: estimated glomerular filtration rate 


\section{INTRODUCTION}

Although complications such as Diabetic Kidney Disease (DKD) in early onset Type1 Diabetes Mellitus (T1DM) in children are usually not detected clinically until reaching adulthood, the underlying pathology is likely to begin in childhood. Indeed, structural changes in the kidney have been reported in humans and animal models early in the course of diabetes mellitus (DM) [1,2]. Moreover, a 'non-albuminuric' form of DKD is becoming a better accepted and recognised clinical phenotype [3]. Although glomerular pathology may be the earliest structural event in DKD, tubular injury is also involved at an early stage [4]. Therefore, biomarkers that reflect both glomerular and tubular injury may prove useful in the early detection of DKD. Moreover, a comprehensive kidney biomarker panel would ideally include both biomarkers of tubular function and structure/injury concurrently to overcome limitations of a single biomarker approach such as albuminuria [5]

The need for early and reliable biomarkers of DKD, other than microalbuminuria alone, is increasingly important, not only in screening for DKD and its earlier detection, but also as potential clinical trial endpoints following an intervention. Currently, patients with non-albuminuric DKD are largely excluded from early (Phase 2) clinical trials typically of 6 to 12 months duration, because albuminuria reduction is still the most widely used surrogate endpoint for new drug treatment in DKD clinical trials $[6,7]$.

The free form of Retinol-Binding Protein 4 (fRBP4) is a $21 \mathrm{kDa}$ low molecular weight protein (LMWP) recognized as a functional biomarker of the proximal tubule (PT) in the setting of acute and chronic tubular dysfunction [8]. There is clinical evidence that the free form of RBP4 is a more sensitive marker of proximal renal tubular dysfunction than measurement of total RBP4, which is used currently [9]. Previous studies have shown elevated urinary RBP4 in patients with T1DM [10,11]. One hypothesis we wanted to test is that small increases in albumin leakage across the glomerulus in early DM may not be sufficient to reach the clinically defined microalbuminuria threshold, but could be detected indirectly and earlier in T1DM by measurement of increased UfRBP4 excretion; competition for reuptake between albumin and LMWP is a possible mechanism for this [12].

Kidney injury molecule (KIM)-1 is an immunoglobulin superfamily protein that is markedly upregulated in the proximal tubule of the injured or diseased kidney, and its urinary levels have been reported to be higher earlier in patients with T1DM and progressive DKD [13,14]. It is considered a structural biomarker 
that is expressed on the apical membrane of proximal tubule cells and may reflect the severity of tubular cell injury [15]. Recently, a relationship between KIM-1 expression and fibrosis-inflammation in DKD patients has been shown, making KIM-1 itself a potentially attractive therapeutic target in DKD [13].

Urinary microRNAs are another recently explored means of studying the kidney, reflecting structural, functional and pathophysiological pathways along the nephron. Using a profiling approach of 754 microRNAs in pooled urine samples of DKD patients, miR-155, miR-126 and miR-29b were significantly increased and this has been confirmed in an independent cohort of patients with DKD, with DM without DKD, and in controls [16]. Based on these reported findings, we included these three microRNAs in our study.

In view of the glomerular-tubular interplay in protein handling, the concept of DKD as a glomerulotubular disorder, and existing data supporting increased excretion of UfRBP4, KIM-1 and microRNAs in patients with longstanding DM, we designed the present study to explore several potential kidney injury biomarkers in children and young adults with different durations of T1DM.

Our principal aim was to determine whether a panel of biomarkers that includes UfRBP4 (glomerular and tubular disfunction), KIM-1 (an early and widely recognized marker of tubular injury and DKD progression) and the three microRNAs, miR-155, miR-126 and miR-29b, might prove useful early renal biomarkers in a normoalbuminuric cohort of young diabetic patients, and if there is any correlate with diabetic control and disease duration. 


\section{MATERIALS and METHODS}

Study design, patient selection and procedures

All subjects were recruited from the T1DM Outpatient Clinic at the Paediatric Service of Azienda SocioSanitaria Territoriale (ASST) Spedali Civili di Brescia. Healthy controls were siblings of the diabetic patients in the clinic. Recruitment began in July 2017 and was completed in June 2018. Specimens preserved on dry ice were sent to the Core Biochemical Assay Laboratory (CBAL) of Cambridge University Hospitals NHS Foundation Trust, UK to measure UfRBP4, Ualb and KIM-1 and to the Wales Kidney Research Unit (Cardiff, United Kingdom) to measure microRNAs.

Inclusion criteria for Short Duration (SD) T1DM patients were onset of T1DM $\leq 2.5$ years; for the Long Duration (LD) T1DM group onset of $\mathrm{T} 1 \mathrm{DM} \geq 10$ years. The SD group was selected to detect any very early change in urine biomarkers excretion as according to current guidelines, the screening for DKD in T1DM begins only after 5 years from diagnosis [17]. The cut off of ten years to classify adolescents as longstanding disease was considered a reasonable time period for adolescents still in paediatric follow-up, since childhood onset of T1DM has a bimodal distribution, with one peak at four to six years of age and a second in early puberty. Healthy controls $(\mathrm{H})$ had no evidence of DM determined by random fasting blood glucose measurement over the six months before study. Exclusion criteria for all subjects included: paediatric chronic kidney disease (CKD), albuminuria (albumin-to-creatinine ratio $>3 \mathrm{mg} / \mathrm{mmol}$ ) [18], persistent haematuria on dipstick testing, congenital anomalies of the kidney and urinary tract (CAKUT), chronic hypertension, inflammatory or neoplastic diseases, liver disease, recurrent urinary tract infection, presence of Type 2 DM, age $<6$ months and $>19$ years. Autoimmune thyroiditis or celiac disease were not exclusion criteria.

Urine for routine analysis was collected as a midstream second void in the morning and sent immediately to the local clinical biochemistry laboratory. Urine for measurement of Urine free Retinol-Binding Protein 4 (UfRBP4), urinary albumin (Ualb), KIM-1 and microRNAs was put on wet ice immediately and frozen at-$80{ }^{\circ} \mathrm{C}$ within one hour. Diabetic patients were also tested for asymptomatic urinary tract infection by urine routine culture. Pre-analytical procedures were carried out with standardized protocols for all patients. This is crucial, especially considering the sensitivity of proteins to degradation and the unfavourable milieu of 
urine as a source of biological material. RBP in urine samples is unaffected by freezing at $-70^{\circ} \mathrm{C}$ for shortterm storage [19] and $\mathrm{KIM}-1$ is stable at $-80^{\circ} \mathrm{C}$ for up to 5 years [20].

For diabetic patients, after an overnight fast, measurements included glycated haemoglobin, blood glucose, triglycerides, total cholesterol, high density lipoprotein, antithyroid antibodies, antitransglutaminase antibodies, thyroid-stimulating hormone, serum creatinine, urate, aspartate aminotransferase, alanine aminotransferase and gamma-glutamyl transferase.

Except for three patients, urine and blood tests were collected on the same day. Any potential confounders, such as fever, severe exercise and vaccinations were avoided during the three days before collection.

Serum creatinine was not measured in healthy controls because of ethical restrictions for venepuncture in healthy children.

BMI was calculated as weight $(\mathrm{Kg})$ divided by height squared $\left(\mathrm{m}^{2}\right)$. We used an online calculator that provides BMI, percentile and z-score [21] BMI was age- and sex-adjusted [22]. Blood pressure percentiles were calculated for each patient.

Guidelines from the American Diabetes Association (ADA) and the International Society for Paediatric and Adolescent Diabetes (ISPAD) specify a patient target of $\mathrm{HbAlc}<59 \mathrm{mmol} / \mathrm{mol}$ and such patients are considered to have good glycaemic control [17].

T1DM-related complications were defined as any acute complications requiring admission to hospital.

\section{Measurement of UfRBP4, Ualb, KIM-1 and MicroRNAs}

Urine creatinine was measured by the Siemens Dimension ${ }^{\circledR}$ RxL enzymatic creatinine assay. Two minor modifications were made to the original UfRBP4 assay to improve assay performance at low analyte concentrations: sample pre-dilution was 1 in 2 instead of 1 in 5 and an additional low standard was added to the standard curve. The lower limit of detection (corrected for dilution) of UfRBP4 in the original urine was $1.0 \mu \mathrm{g} / \mathrm{L}$. KIM-1 was measured by Quantikine ${ }^{\mathrm{TM}}$ Elisa (R\&D Systems, MN, U.S.A.). Methods for microRNAs profiling have been described previously [16]. 


\section{$\underline{\text { Data analysis }}$}

Continuous variables with a normal distribution were expressed as mean \pm standard deviation (SD); variables with a non-normal distribution as median and interquartile range (quartile 1 and quartile 3 ). To test for normality, we used the D'Agostino-Pearson Test. ANOVA, Unpaired Student t test, Wilcoxon rank-sum and Mann-Whitney tests were used as appropriate for comparison of continuous variables, and the Chisquared test was used for comparison of categorical variables. Pearson and Spearman's correlation analysis was used to detect correlation. Multivariable logistic regression analyses were performed to test the independent strengths of associations. Statistical analyses were conducted with GraphPad Prism ${ }^{\circledR} 8$ and STATA $^{\circledR}$. For microRNAs, analysis was carried out in GraphPad Prism® 6 by unpaired t-test with Welch’s correction. Data were normalized to endogenous control miR-191 and are presented as mean +/- SEM A two-tailed p-value $<0.05$ was considered significant for all studies.

\section{RESULTS}

Over one year, 93 subjects were screened for the study, of whom 80 were recruited and included in the final analysis. Thirteen patients were excluded as they met one or more exclusion criteria. The distribution of the patients across the three groups and the exclusion criteria for each patient are shown in Figure 1.

Fig. 1 Patient recruitment and distribution into the different study groups.

\section{Baseline features}

Baseline demographic and clinical features of the subjects are shown in Table 1 below and supplementary

Table 4. The biochemical and metabolic characteristics of the diabetic children are shown in supplementary

Table 5 .

Table 1 Baseline features of the study population 


\begin{tabular}{|c|c|c|c|c|}
\hline & $\begin{array}{c}\text { Short } \\
\text { Duration } \\
\text { Group }\end{array}$ & $\begin{array}{c}\text { Long } \\
\text { Duration } \\
\text { Group }\end{array}$ & $\begin{array}{l}\text { Healthy } \\
\text { Group }\end{array}$ & $\begin{array}{c}\text { p } \\
\text { value }\end{array}$ \\
\hline $\begin{array}{c}\text { Age } \\
\text { (years) }\end{array}$ & $11.8(6.6,12.6)$ & $16.7(14.7,18.0)$ & $11.0(9.4,13.4)$ & $<0.0001^{\mathrm{a}}$ \\
\hline $\begin{array}{c}\text { Age at T1DM onset } \\
(\text { years })\end{array}$ & $9.7(4.5,12.4)$ & $3.3(2.4,5.1)$ & - & $<0.0001$ \\
\hline $\begin{array}{c}\text { Duration of T1DM } \\
\text { (years) }\end{array}$ & $1.9(1.1,2.1)$ & $12.4(11.6,14.0)$ & - & $<0.0001$ \\
\hline $\begin{array}{l}\text { Daily insulin dose } \\
\text { (units) }^{\text {b }}\end{array}$ & $27 \pm 15$ & $50 \pm 20$ & - & $<0.0001$ \\
\hline $\begin{array}{c}\text { HbA1c } \\
(\mathrm{mmol} / \mathrm{mol})\end{array}$ & $49(52,59)$ & $60(51,67)$ & - & 0.03 \\
\hline $\begin{array}{c}\text { Serum creatinine } \\
(\mathbf{m g} / \mathbf{d L})\end{array}$ & $0.51 \pm 0.15$ & $0.71 \pm 0.13$ & - & $<0.0001$ \\
\hline $\begin{array}{c}\text { eGFR }(\mathrm{mL} / \mathrm{min} / \mathbf{1 . 7 3} \\
\left.\mathbf{m}^{2}\right)^{\mathbf{d}}[23]\end{array}$ & $160 \pm 26$ & $145 \pm 21$ & - & 0.006 \\
\hline
\end{tabular}

a Significantly higher in LD group compared to both SD and H groups.

${ }^{\mathrm{b}}$ Daily insulin dose overuri the last three months

${ }^{\mathrm{c}}$ Normal range $(20-42 \mathrm{mmol} / \mathrm{mol})$

${ }^{\mathrm{d}}$ Estimated glomerular filtration rate (eGFR) is calculated using the Schwartz formula for children and young adults between the age of 1 and 19

\section{Principal biomarkers}

The first aim of the study was to establish whether a functional tubular biomarker such as UfRBP4 and a tubular injury biomarker such as KIM-1 were significantly different between patients with a short duration of T1DM and healthy participants without DM, and between short and long duration T1DM patients. We found that both biomarkers were not significantly different across all paediatric groups (Table 2 and Fig. 2). 
$\underline{\text { Table } 2}$ Principal biomarkers in the study population.

\begin{tabular}{|l|c|c|c|c|}
\hline & $\begin{array}{c}\text { Short Disease } \\
\text { Group }\end{array}$ & $\begin{array}{c}\text { Long Disease } \\
\text { Group }\end{array}$ & Healthy & p- \\
\hline $\begin{array}{l}\text { UfRBP4 } \\
\text { (ug/mmol) }\end{array}$ & $1.13(0.6,2.1)$ & $1.15(0.7,1.6)$ & $1.16(0.43,1.81)$ & 0.7 \\
\hline $\begin{array}{l}\text { Ualb } \\
(\mathbf{m g} / \mathbf{m m o l})\end{array}$ & $0.6(0.4,0.8)$ & $0.4(0.4,0.9)$ & $0.7(0.4,1.0)$ & 0.5 \\
\hline $\begin{array}{l}\text { KIM-1 } \\
(\mathbf{n g} / \mathbf{m L})\end{array}$ & $0.09(0.04,0.15)$ & $0.06(0.04,0.13)$ & $0.06(0.04,0.08)$ & 0.07 \\
\hline
\end{tabular}

On average, all three groups had normal and not significantly different Ualb. Among microRNAs, miR$29 \mathrm{~b}$ was higher in diabetic children overall compared with $\mathrm{H}(\mathrm{p}=0.03)$, whereas miR-155 and miR-126 were not significantly different (Figure 3). No differences were found between the SD and LD group in expression of the three microRNAs. No associations were identified between urinary excretion of the microRNAs and sex, age, eGFR, Ualb and glycaemic control as determined by HbA1c measurement.

Fig.2 UfRBP4 and KIM-1 across the study groups. Both biomarkers were not significantly different across children with or without T1DM.

Fig.3 Expression of miR-126, miR-29b and miR-155 in healthy children compared to diabetic children (SD and LD groups). miR$29 \mathrm{~b}$ was higher in diabetic children overall compared to controls $(* \mathrm{p}=0,03)$, whereas miR-155 and miR-126 were similar across the two groups.

UfRBP4, Ualb and KIM-1 showed no significant differences by sex, metabolic control of T1DM or T1DMrelated complications requiring admission to hospital (Table 3). UfRBP4 was correlated with Ualb in the whole population and in each group of the study (Figure 4), whereas KIM-1 did not correlate with either UfRBP4 or UAlb (supplementary figure 5) 
$\underline{\text { Table } 3}$ Comparison between the different subgroups for UfRBP4, Ualb and KIM-1.

\begin{tabular}{|c|c|c|c|c|c|c|c|c|c|c|c|c|}
\hline & Male & Female & $p$ & $\begin{array}{l}\text { HbA1c } \\
\text { target } \leq 59 \\
\mathrm{mmol} / \mathrm{mol}\end{array}$ & $\begin{array}{l}\text { HbA1c } \\
\text { target }>59 \\
\mathrm{mmol} / \mathrm{mol}\end{array}$ & $p$ & $\begin{array}{l}\text { T1DM- } \\
\text { complications }\end{array}$ & $\begin{array}{l}\text { No T1DM- } \\
\text { complications }\end{array}$ & $p$ & $\begin{array}{l}\text { Hyper- } \\
\text { filtration }^{a}\end{array}$ & $\begin{array}{l}\text { No Hyper- } \\
\text { filtration }\end{array}$ & $p$ \\
\hline $\begin{array}{l}\text { UfRBP4 } \\
(\boldsymbol{\mu g} / \mathrm{mmol})\end{array}$ & $\begin{array}{c}1.1 \\
(0.5,1.5)\end{array}$ & $\begin{array}{c}1.1 \\
(0.6,2.4)\end{array}$ & 0.3 & $\begin{array}{c}1.2 \\
(0.8,2.0)\end{array}$ & $\begin{array}{c}1.1 \\
(0.6,1.6)\end{array}$ & 0.3 & $\begin{array}{c}1.1 \\
(0.7,1.8)\end{array}$ & $\begin{array}{c}1.2 \\
(0.6,1.9)\end{array}$ & 0.9 & $\begin{array}{c}1.0 \\
(0.6,1.6)\end{array}$ & $\begin{array}{c}1.2 \\
(0.7,1.2)\end{array}$ & 0.3 \\
\hline $\begin{array}{l}\text { Ualb } \\
(\mathrm{mg} / \mathrm{mmol})\end{array}$ & $\begin{array}{c}0.5 \\
(0.4,0.9)\end{array}$ & $\begin{array}{c}0.7 \\
(0.4,1.4)\end{array}$ & 0.1 & $\begin{array}{c}0.6 \\
(0.4,0.8\end{array}$ & $\begin{array}{c}0.4 \\
(0.3,1.0)\end{array}$ & 0.6 & $0.7 \pm 0.5$ & $0.8 \pm 0.6$ & 0.7 & $0.7 \pm 0.6$ & $0.9 \pm 0.7$ & 0.3 \\
\hline $\begin{array}{l}\text { KIM-1 } \\
(n g / m L)\end{array}$ & $\begin{array}{c}0.07 \\
(0.04,0.11)\end{array}$ & $\begin{array}{c}0.06 \\
(0.04,0.15)\end{array}$ & 0.7 & $\begin{array}{c}0.06 \\
(0.04,0.11)\end{array}$ & $\begin{array}{c}0.13 \\
(0.05,0.15)\end{array}$ & 0.1 & $\begin{array}{c}0.06 \\
(0.04,0.12)\end{array}$ & $\begin{array}{c}0.06 \\
(0.04,0.10)\end{array}$ & 0,7 & $\begin{array}{c}0.07 \\
(0.05,0.16)\end{array}$ & $\begin{array}{c}0.08 \\
(0.04,0.13)\end{array}$ & 0,5 \\
\hline
\end{tabular}

${ }^{a}$ Definition of Hyperfiltration: eGFR that exceeds two standard deviations above mean GFR of an age-matched normal (i.e., without evidence of renal disease) population, where glomerular filtration rate was determined by inulin clearance [24].

$\mathrm{p}=\mathrm{p}$-value

Fig.4 Relationship between UfRBP4 and Ualb across all study groups. UfRBP4: urine free retinol-binding protein 4 (ug/mmol); Ualb: urinary albumin expressed as albumin to creatinine ratio $(\mathrm{mg} / \mathrm{mmol})$. 


\section{DISCUSSION}

In our short-disease (SD) cohort, UfRBP4 was not different from age-matched healthy controls (H) or from children with longer duration (LD) diabetes. The process underlying increased urinary excretion of fRBP4 appears relatively late in the course of T1DM, with studies of URBP4 indicating that increases in this protein are relatively common in late stage $\mathrm{T} 1$ and $\mathrm{T} 2 \mathrm{DM}$ in adults [9,21] [25]. The current explanation for increased excretion of URBP4 is tubular dysfunction and disease. However, with predominant tubular damage, as in the renal Fanconi syndrome, the increase in fRBP4 is several orders of magnitude higher [26]. The absence of even a mild increase in UfRBP4 probably excludes an early tubular abnormality in T1DM, at least one that affects tubular protein handling. A recent model of glomerular filtration and tubular absorption of RBP4 by Edwards et al. suggests that, if proximal tubular reabsorption is intact, measurement of urine RBP4 is not superior to albumin in detecting increases in glomerular permeability [27]. The clinical results here are consistent with this prediction.

KIM-1 is a non-invasive kidney biomarker that has shown reliable performance in identifying children with chronic kidney disease at risk of progression [28] . In T1DM, KIM-1 was overexpressed very early in the course of the disease with a predictive value of progression of DKD [14], and was linked to reduced kidney function in a GWAS study [29]. Recently, the association of endocytic function of KIM-1 on epithelial tubular cells of PT and pathogenesis of DKD has been reported, making inhibition of KIM-1 a potentially attractive therapeutic strategy to prevent progression of DKD [13]. Like UfRBP4, KIM-1 showed no elevation in children with short duration DM compared with healthy counterparts, as well as no overexpression in the LD group. KIM-1, a validated kidney injury biomarker in DKD and in children did not detect signs of kidney damage in our study population.

We also explored the expression of three different microRNAs reported previously to show a microRNA signature associated with DKD [16]. One of the advantages of using non-invasive biomarkers like microRNAs is their stability in many biological fluids. Urine is an unstable milieu in which many proteins undergo degradation. Urinary expression of miR-155 and miR-126 was similar across the three paediatric groups, whereas miR-29b was more highly expressed in the pooled diabetic group compared with healthy controls. Although no differences were found when the SD group was compared with the LD group, miR29b may still provide an early signal for DKD, since it has been found to be enriched in glomerular 
endothelial cells and released from these cells in response to DKD-linked cytokines [16]. miR-155 and miR126 were found to be elevated in cohorts with established DKD in other studies, but we did not find this in early stages of T1DM in our carefully phenotyped patients with normal renal function and no microalbuminuria. These findings are also consistent with our UfRBP4 and KIM-1 results in detecting no sign of early renal involvement in T1DM patients compared with controls. Recent improvements in the treatment of T1DM have resulted in better metabolic control, which will decrease the incidence of complications of T1DM, including nephropathy [30,31].

A surprising finding was the lack of any increase in biomarkers in the LD group. The absence of any difference between LD and healthy controls suggests that our negative findings indicate the absence of nephropathy in this group of young T1DM patients, regardless of the duration of diabetes. The susceptibility to DKD reflects genetically and epigenetically determined differences in the kidney response to metabolic and autoimmune disease [32] that are magnified in the presence of hyperglycemia [33]. In patients with T1 and T2 diabetes, a cluster of insulin-resistant individuals has been found to have a significantly higher risk of developing DKD [34]. As already mentioned, the absence of nephropathy in our cohort of children may reflect optimal clinical management and glycaemic control [30]. In children, more intensive insulin regimens are recommended, because they are more likely to reach and maintain glycated haemoglobin (HbA1C) targets with better clinical outcomes [35].

Our study has two main limitations. We could not evaluate routine blood chemistry in healthy children because of ethical restrictions. Moreover, the controls were all siblings of patients with T1DM and their lifetime risk of developing DM is known to be increased relative to the general population [36]. However, the controls did have a random fasting glucose measurement within six months of urine collection.

The current literature describes very few studies evaluating a panel of urinary biomarkers in diabetic children and adolescents, and none has recruited patients with T1DM of short duration to compare with those of longer duration. Study of T1DM does make interpretation of our results easier, because of the known time of onset of diabetes and the absence of any potentially confounding co-morbidities in otherwise healthy children, in contrast with T2DM.

Taken together, UfRBP4, KIM-1, miR-155 and miR-126 were not increased in young T1DM patients with normal renal function and no urinary albumin excretion. These biomarkers have been reported to be 
elevated in cohorts with established DKD, mainly in adults, in other studies; however, we have not found them to be increased in carefully phenotyped children, adolescents and young adults with T1DM, and they are unlikely to be of added value in screening for early DKD in the absence of albuminuria.

\section{SUMMARY CONCLUSIONS}

A panel of biomarkers, including functional and structural biomarkers such as UfRBP4 and KIM-1, and three tested microRNAs linked previously to DKD in an adult setting showed no differences in children, adolescents, and young adults with different durations of T1DM and without other evidence of nephropathy. These findings support the specificity of the biomarkers tested for those diabetics with nephropathy. Further studies are required to determine whether very early nephropathy is discernible using these biomarkers. Our findings also suggest that children with T1DM today have a more favourable renal outlook, probably the result of improvements in early diagnosis and routine clinical care.

\section{DECLARATIONS}

\section{Ethics approval and consent to participate}

All procedures were in accordance with the ethical standards of the Institution and/or National Research Committee and with the 1975 Helsinki Declaration and later amendments or comparable ethical standards. The study was approved by the Ethics Committee of Azienda Socio-Sanitaria Territoriale degli Spedali Civili di Brescia. All participants provided written informed consent. For minors, written informed consent was obtained from both parents and patients were also asked to give assent before the study. Patients aged 18 years or over provided written informed consent.

\section{Consent for publication}

Not applicable 


\section{Availability of data and materials}

The datasets used and/or analysed during the current study are available from the corresponding author on reasonable request

\section{Competing interests}

Authors declared no conflicts of interest.

\section{Funding}

The study was supported by University College London.

\section{Authors' contributions}

Initial idea was conceived by L.Z., A.G.W.N. and R.J.U.; A.G.W.N., L.Z. and R.J.U. contributed to study design; L.Z, C.C. E.P. and B.F. were involved in patient's recruitment and data gathering; K.B, K.S. and D.F. performed laboratory analysis; G.C. and P.M.F. contributed to statistical analysis; L.Z., A.G.W.N., D.F. contributed to drafting of the manuscript. L.Z., A.G.W.N. and R.J.U. supervised all the phases of the study and manuscript drafting. All authors have read and approved the current version of the article.

\section{Acknowledgements}

We thank all study participants, their families and nursing staff for their contributions to the study.

\section{Authors' information}

R.J.U. is currently employed by AstraZeneca BioPharmaceuticals R\&D.

D.F. has European Patent Application 17702919.6 issued to Cardiff University. 


\section{References}

1. Vallon V, Thomson SC. Renal function in diabetic disease models: the tubular system in the pathophysiology of the diabetic kidney. Annual review of physiology. Annual Reviews; 2012;74.

2. Fioretto P, Mauer M. Histopathology of diabetic nephropathy. Seminars in nephrology. Elsevier; $2007 ; 27(2)$.

3. Viazzi F, Piscitelli P, Giorda C, Ceriello A, Genovese S, Russo GT, et al. Association of kidney disease measures with risk of renal function worsening in patients with hypertension and type 2 diabetes. Journal of Diabetes and its Complications. 2017;31(2).

4. Zeni L, Norden AG, Cancarini G, Unwin RJ. A more tubulocentric view of diabetic kidney disease. Journal of nephrology. 2017;30(6).

5. Ix JH, Shlipak MG. The Promise of Tubule Biomarkers in Kidney Disease: A Review. American Journal of Kidney Diseases. Elsevier; 2021;78(5).

6. Pollock C, Stefánsson B, Reyner D, Rossing P, Sjöström CD, Wheeler DC, et al. Albuminuria-lowering effect of dapagliflozin alone and in combination with saxagliptin and effect of dapagliflozin and saxagliptin on glycaemic control in patients with type 2 diabetes and chronic kidney disease (DELIGHT): a randomised, double-blind, placebo-controlled trial. The Lancet Diabetes \& Endocrinology. Elsevier; 2019;7(6).

7. Palmer SC, Tendal B, Mustafa RA, Vandvik PO, Li S, Hao Q, et al. Sodium-glucose cotransporter protein-2 (SGLT-2) inhibitors and glucagon-like peptide-1 (GLP-1) receptor agonists for type 2 diabetes: systematic review and network meta-analysis of randomised controlled trials. British Medical Journal Publishing Group; 2021;372.

8. Norden AG, Lapsley M, Unwin RJ. Urine retinol-binding protein 4: a functional biomarker of the proximal renal tubule. Advances in clinical chemistry. Elsevier; 2014;63.

9. Burling KA, Cutillas PR, Church D, Lapsley M, Norden AG. Analysis of molecular forms of urine Retinol-Binding Protein in Fanconi Syndrome and design of an accurate immunoassay. Clinica chimica acta. 2012;413(3-4).

10. Soggiu A, Piras C, Bonizzi L, Hussein HA, Pisanu S, Roncada P. A discovery-phase urine proteomics investigation in type 1 diabetes. Acta Diabetologica. 2012;49(6).

11. Schultz CJ, Dalton RN, Neil HAW, Konopelska-Bahu T, Dunger DB, Group ORPS. Markers of renal tubular dysfunction measured annually do not predict risk of microalbuminuria in the first few years after diagnosis of Type I diabetes. Diabetologia. 2001;44(2).

12. Bernard A, Amor AO, Viau C, Lauwerys R. The renal uptake of proteins: a nonselective process in conscious rats. Kidney international. 1988;34(2).

13. Mori Y, Ajay AK, Chang J-H, Mou S, Zhao H, Kishi S, et al. KIM-1 mediates fatty acid uptake by renal tubular cells to promote progressive diabetic kidney disease. Cell Metabolism. Elsevier; 2021;33(5).

14. Vaidya VS, Niewczas MA, Ficociello LH, Johnson AC, Collings FB, Warram JH, et al. Regression of microalbuminuria in type 1 diabetes is associated with lower levels of urinary tubular injury biomarkers, kidney injury molecule-1, and N-acetyl- $\beta$-D-glucosaminidase. Kidney international. Elsevier; 2011;79(4).

15. Van Timmeren MM, Vaidya VS, van Ree RM, Oterdoom LH, de Vries AP, Gans RO, et al. High urinary excretion of kidney injury molecule-1 is an independent predictor of graft loss in renal transplant recipients.

Transplantation. NIH Public Access; 2007;84(12). 
16. Beltrami C, Simpson K, Jesky M, Wonnacott A, Carrington C, Holmans P, et al. Association of elevated urinary miR-126, miR-155, and miR-29b with diabetic kidney disease. The American journal of pathology. 2018;188(9).

17. Association AD. 12. Children and adolescents: standards of medical care in diabetes-2018. Diabetes care. $2018 ; 41(1)$.

18. de Boer IH, Caramori ML, Chan JC, Heerspink HJ, Hurst C, Khunti K, et al. KDIGO 2020 clinical practice guideline for diabetes management in chronic kidney disease. Kidney international. Elsevier; 2020;98(4S).

19. Mao J, Chen S, Na Z, Xhang Y, Huang Y, Li Y. Frozen storage of urine samples before ELISA measurement of retinol-binding protein. Clinical chemistry. 1996;42(3).

20. Schuh MP, Nehus E, Ma Q, Haffner C, Bennett M, Krawczeski CD, et al. Long-term stability of urinary biomarkers of acute kidney injury in children. American Journal of Kidney Diseases. Elsevier; 2016;67(1).

21. Calculator: Body mass index (BMI) percentiles for girls (2 to 20 years) - UpToDate

22. Laurson KR, Eisenmann JC, Welk GJ. Body fat percentile curves for US children and adolescents. American journal of preventive medicine. 2011;41:(4).

23. Schwartz GJ, Munoz A, Schneider MF, Mak RH, Kaskel F, Warady BA, et al. New equations to estimate GFR in children with CKD. Journal of the American Society of Nephrology. 2009;20(3).

24. Helal I, Fick-Brosnahan GM, Reed-Gitomer B, Schrier RW. Glomerular hyperfiltration: definitions, mechanisms and clinical implications. Nature Reviews Nephrology. Nature Publishing Group; 2012;8(5).

25. Park SE, Lee NS, Park JW, Rhee E-J, Lee W-Y, Oh K-W, et al. Association of urinary RBP4 with insulin resistance, inflammation, and microalbuminuria. European Journal of Endocrinology. 2014;171(4).

26. Norden AG, Burling KA, Zeni L, Unwin RJ. A New Estimate of the Glomerular Sieving Coefficient for Retinol-Binding Protein4 Suggests it is not Freely-filtered. Kidney International Reports. 2019; 4(7).

27. Edwards A, Christensen EI, Unwin RJ, Norden AG. Predicting the protein composition of human urine in normal and pathological states: Quantitative description based on Dent1 disease (CLCN5 mutation). The Journal of Physiology. Wiley Online Library; 2021;599(1).

28. Greenberg JH, Abraham AG, Xu Y, Schelling JR, Feldman HI, Sabbisetti VS, et al. Urine biomarkers of kidney tubule health, injury, and inflammation are associated with progression of CKD in children. Journal of the American Society of Nephrology. Am Soc Nephrol; 2021;32(10).

29. Panduru NM, Sandholm N, Forsblom C, Saraheimo M, Dahlström EH, Thorn LM, et al. Kidney injury molecule-1 and the loss of kidney function in diabetic nephropathy: a likely causal link in patients with type 1 diabetes. Diabetes Care. Am Diabetes Assoc; 2015;38(6).

30. Group AC. Intensive blood glucose control and vascular outcomes in patients with type 2 diabetes. New England journal of medicine. Mass Medical Soc; 2008;358(24).

31. Nordwall M, Bojestig M, Arnqvist HJ, Ludvigsson J. Declining incidence of severe retinopathy and persisting decrease of nephropathy in an unselected population of Type 1 diabetes - the Linköping Diabetes Complications Study. Diabetologia. Springer; 2004;47(7).

32. Gu HF. Genetic and epigenetic studies in diabetic kidney disease. Frontiers in genetics. Frontiers Media SA; 2019;10:507. 
33. Freedman BI, Bostrom M, Daeihagh P, Bowden DW. Genetic factors in diabetic nephropathy. Clinical journal of the American Society of Nephrology. Am Soc Nephrol; 2007;2(6).

34. Ahlqvist E, Storm P, Käräjämäki A, Martinell M, Dorkhan M, Carlsson A, et al. Novel subgroups of adult-onset diabetes and their association with outcomes: a data-driven cluster analysis of six variables. The lancet Diabetes \& endocrinology. Elsevier; 2018;6(5).

35. Chiang JL, Kirkman MS, Laffel LM, Peters AL. Type 1 diabetes through the life span: a position statement of the American Diabetes Association. Diabetes care. Am Diabetes Assoc; 2014;37(7).

36. Guo S-W, Tuomilehto J. Preferential transmission of type 1 diabetes from parents to offspring: fact or artifact? Genetic Epidemiology: The Official Publication of the International Genetic Epidemiology Society. 2002;23(4). 
Figures

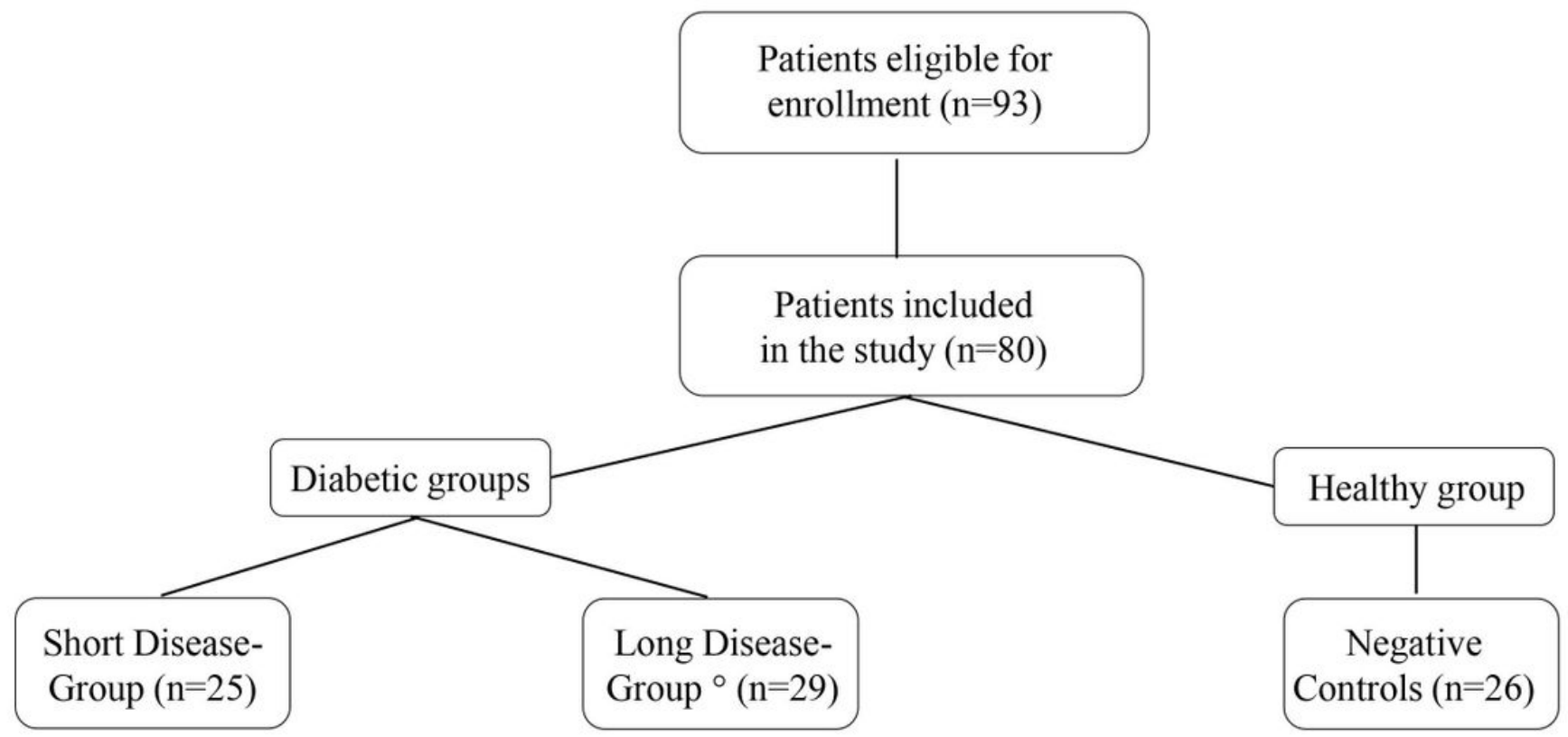

- 3 subjects with blood test and urine test collected in different dates

\section{Figure 1}

Patient recruitment and distribution into the different study groups. 

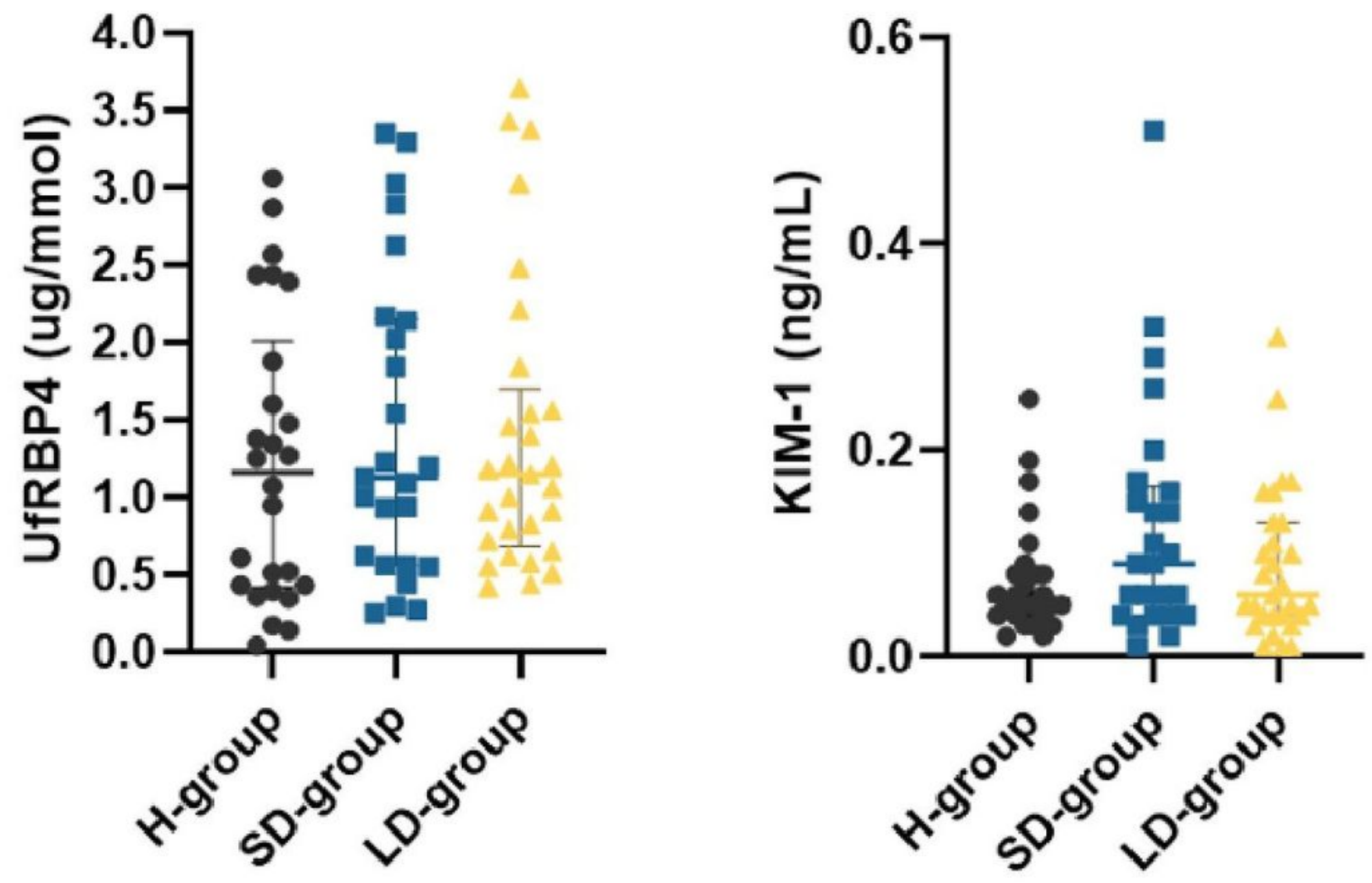

Figure 2

UfRBP4 and KIM-1 across the study groups. Both biomarkers were not significantly different across children with or without T1DM.

Relative expression miR-126

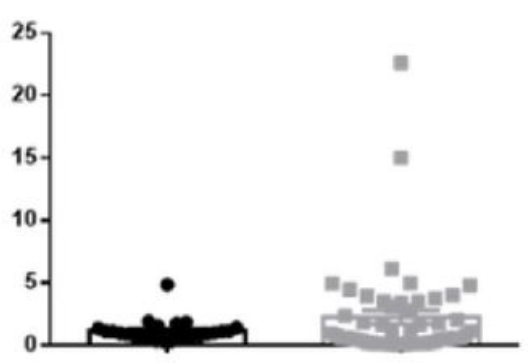

$H$ group SD and LD group
Relative expression miR-29b

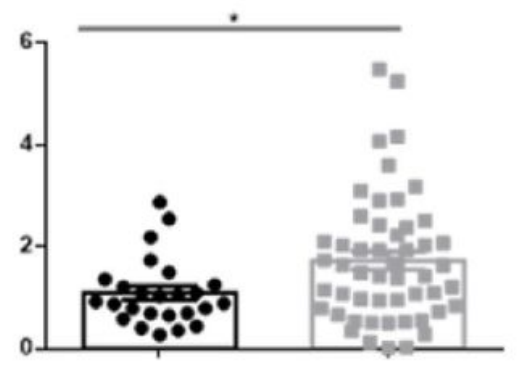

$H$ group SD and LD group
Relative expression miR-155

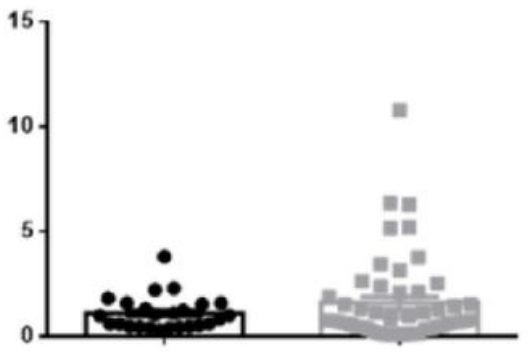

$H$ group SD and LD group

Figure 3 
Expression of miR-126, miR-29b and miR-155 in healthy children compared to diabetic children (SD and LD groups). miR $\otimes 29 b$ was higher in diabetic children overall compared to controls $\left({ }^{*} p=0,03\right)$, whereas miR-155 and miR-126 were similar across the two groups.

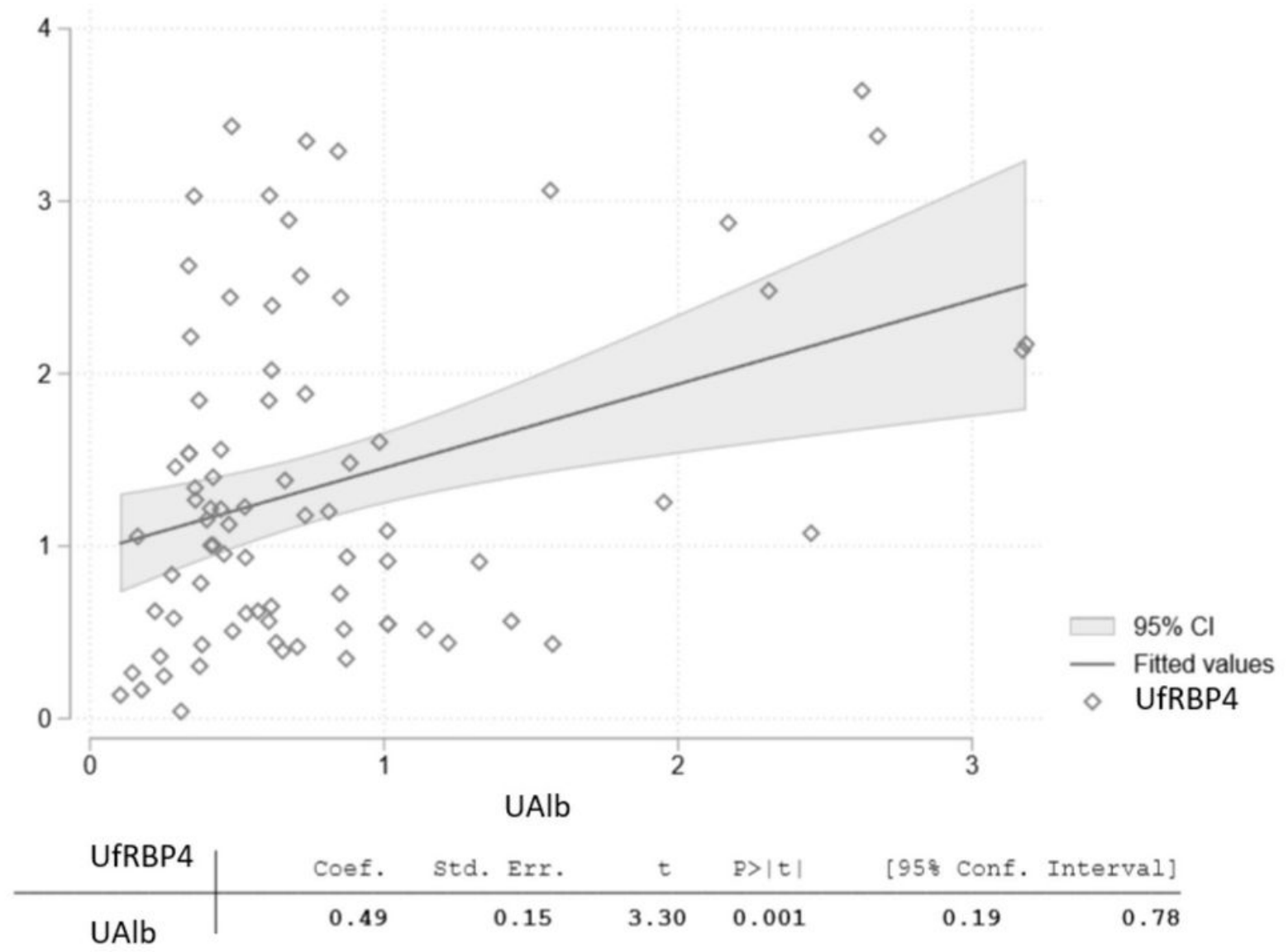

Figure 4

Relationship between UfRBP4 and Ualb across all study groups. UfRBP4: urine free retinol-binding protein 4 (ug/mmol); Ualb: urinary albumin expressed as albumin to creatinine ratio $(\mathrm{mg} / \mathrm{mmol})$.

\section{Supplementary Files}

This is a list of supplementary files associated with this preprint. Click to download.

- SupplementaryMaterial.pdf 